“ (C) 2018 IEEE. Personal use of this material is permitted. Permission from IEEE must be obtained for all other uses, in any current or future media, including

reprinting/republishing this material for advertising or promotional purposes, creating new collective works, for resale or redistribution to servers or lists, or reuse of any copyrighted component of this work in other works." 


\title{
Boost Half-Bridge DC-DC Converter with Reconfigurable Rectifier for Ultra-Wide Input Voltage Range Applications
}

\author{
Dmitri Vinnikov ${ }^{1}$, Andrii Chub ${ }^{1}$, Elizaveta Liivik ${ }^{2}$, Frede Blaabjerg ${ }^{2}$, Yam Siwakoti ${ }^{3}$ \\ ${ }^{1}$ Department of Electrical Power \\ Engineering and Mechatronics \\ Tallinn University of Technology \\ Tallinn, Estonia \\ dmitri.vinnikov@ttu.ee \\ ${ }^{2}$ Department of Energy Technology \\ Aalborg University \\ Aalborg, Denmark \\ fbl@et.aau.dk \\ ${ }^{3}$ School of Electrical, Mechanical \\ and Mechatronic Systems \\ University of Technology Sydney \\ Sydney, Australia \\ yam.siwakoti@uts.edu.au
}

\begin{abstract}
This paper introduces a novel galvanically isolated boost half-bridge dc-dc converter intended for modern power electronic applications where ultra-wide input voltage regulation range is needed. A reconfigurable output rectifier stage performs a transition between the voltage doubler and the full-bridge diode rectifiers and, by this means, extends the regulation range significantly. The converter features a low number of components and resonant soft switching of semiconductors, which result in high power conversion efficiency over a wide input voltage and load range. The paper presents the operating principle, prototype design and experimental study of the proposed converter.
\end{abstract}

Keywords-dc-dc converter; boost half-bridge converter; reconfigurable rectifier; multi-mode control

\section{INTRODUCTION}

Recent increased interest in residential and small commercial renewable energy systems has stimulated the research in the field of galvanically isolated step-up dc-dc converters with wide input voltage and load variation range. Such converters can be used, for instance, in small-scale residential wind turbines with permanent magnet synchronous generators, where the output voltage of the generator can vary in a very wide range [1]-[3]. Another example is the use of photovoltaic microconverters with shade-tolerant maximum power point tracking, which requires at least a six-fold input voltage regulation range to ensure the energy yield from a heavily shaded PV module [4],[5]. The requirements of wide input voltage and load regulation range make the design of the dc-dc converter very challenging, especially from the point of view of weighted efficiency, voltage and current stresses of the components. To satisfy this demand, different novel topologies of galvanically isolated step-up dc-dc converters have recently been investigated, which range from the singleswitch magnetically integrated high-gain dc-dc converters [6] to more complex isolated buck-boost dc-dc converters (IBBCs) [7]. The IBBCs can be categorized either as the multistage converters, i.e. when the buck and boost functions are performed by different switching cells [7]-[9], or as the single-stage ones, where the buck-boost functionality is realized by a single switching cell [10]-[11]. To enhance the performance of the single-stage IBBC further, the topology morphing control could be implemented, which, depending on the operating conditions of the converter, will reconfigure the switching cell to achieve better tradeoff between the power losses in the active switches and the resulting dc gain of the converter [12].

This paper presents an alternative realization approach of the high step-up galvanically isolated dc-dc converter with topology morphing control, where the regulation within the ultra-wide input voltage range is realized by the combination of the current-fed boost half-bridge cell and reconfigurable rectifier at the input and output sides of the converter, correspondingly. Compared to the existing IBBCs, the proposed converter has only three controlled switches and is capable of achieving ten-fold input voltage regulation range with high efficiency.

\section{Proposed CONVERTER AND ITS Multi-Mode CONTROL PRINCIPLE}

The proposed converter is shown in Fig. 1. Its primary (or low-voltage) side is based on the boost half-bridge (BHB) cell, which is a well proven topology for such demanding applications as photovoltaic [13],[14], fuel cells [15],[16], and battery powered systems [17]. Having only two complimentary controlled switches, the BHB stage could be regarded as one of the simplest approaches to the step-up galvanically isolated dc-dc converters, which is capable of regulating up to the four-fold input voltage variations. Moreover, the leakage inductance $L_{l k}$ of the isolation transformer is often used as a resonant inductor of the series

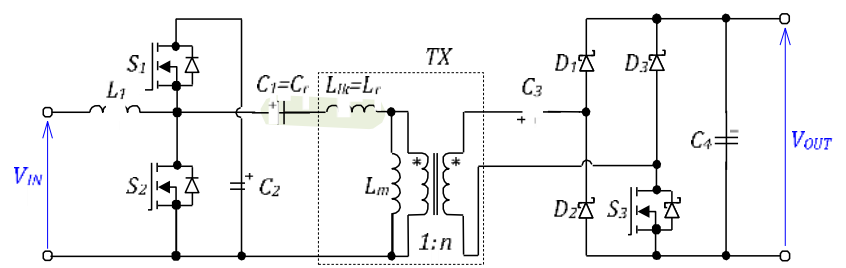

Fig. 1. Boost half-bridge dc-dc converter with reconfigurable rectifier. 
resonant tank formed with the dc-blocking capacitor $C_{l}$ [18] (Fig. 1). The secondary (or high-voltage) side of the converter is based on a reconfigurable rectifier, which, depending on the operation mode, can operate either as a Greinacher voltage doubler rectifier or a full-bridge rectifier. As compared to [19], where a similar approach has been used to widen the output voltage range of the step-up dc-dc converter, the application of the reconfigurable rectifier in the current study results in an extended practical input voltage regulation range of the $\mathrm{BHB}$ by more than twice. Depending on the configuration of the rectifier, the converter can feature two operating modes, which result in different dc voltage gains.

\section{A. Greinacher Voltage Doubler Rectifier (GVDR) Mode}

In this mode, the switch $S_{3}$ is permanently turned ON and the rectifier is operating as a GVDR (Fig. 2a). The duty cycle variation of the main switch $S_{2}$ defines the dc voltage gain. The switch $S_{1}$ in combination with the capacitor $C_{2}$ acts as an active clamping circuit, and it is controlled complementary to $S_{2}$. A dead-time $T_{D T}$ between commutations of $S_{1}$ and $S_{2}$ is needed to avoid short-circuiting of the clamping capacitor $C_{2}$.

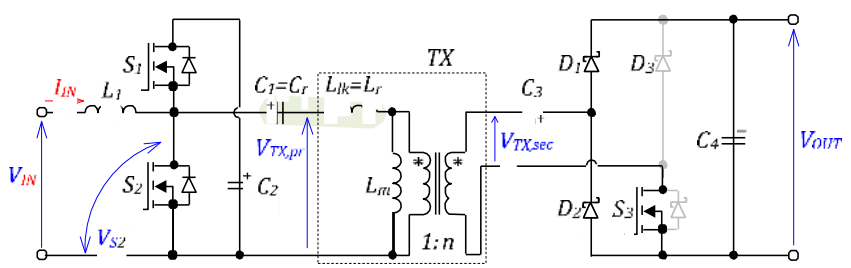

(a)

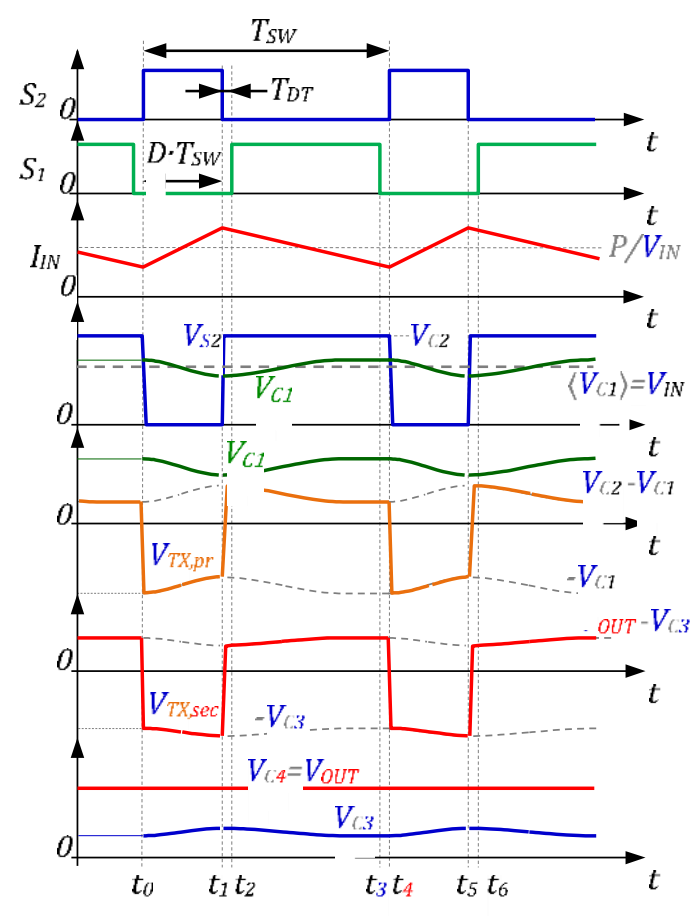

(b)

Fig. 2. Reconfiguration (a) and generalized operating principle $(b)$ of the proposed converter in the GVDR mode.

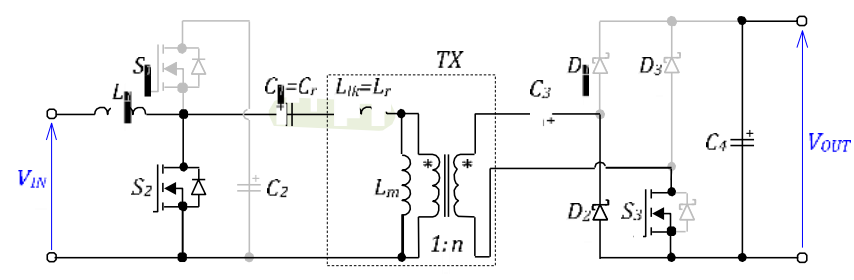

(a)

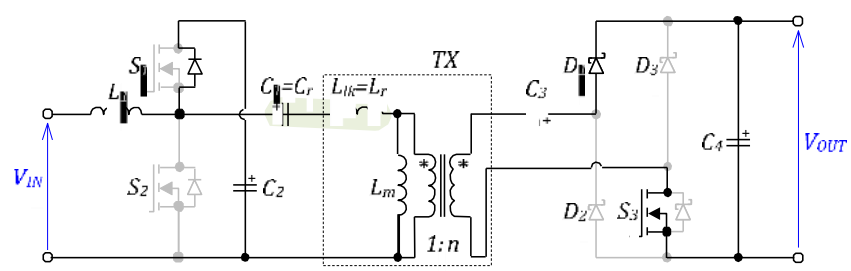

(b)

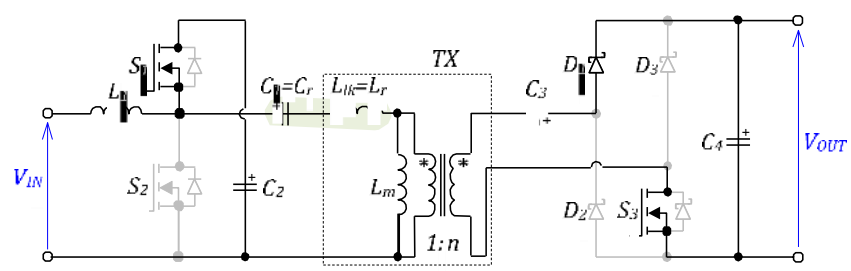

(c)

Fig. 3. Equivalent circuits of the converter operating in the GVDR mode for the time intervals $\left[t_{0} ; t_{1}\right](a),\left[t_{1} ; t_{2}\right](b)$ and $\left[t_{2} ; t_{3}\right](c)$ defined in Fig. $2 b$.

During the time interval $\left[t_{0} ; t_{l}\right]$, the BHB stage is increasing energy stored in the input inductor, while the dc blocking capacitor $C_{1}$ is charging the output capacitor $C_{3}$, as shown in Fig. $3 a$. At the same time, the output capacitor $C_{4}$ is feeding the load. The duration of this interval defines the dc voltage gain of the BHB stage. Commutation of the switches $S_{1}$ and $S_{2}$ is separated by means of the dead-time of duration $\left[t_{1} ; t_{2}\right]$ and $\left[t_{3} ; t_{4}\right]$ (Fig. 3b). During the dead-time, the body diode of the switch $S_{1}$ clamps voltage of the switch $S_{2}$ at the voltage of the capacitor $C_{2}$ and conducts the current difference between the input current and the transformer current. During the remaining time of the switching period $\left[t_{2} ; t_{3}\right]$, the output capacitor $C_{4}$ is being charged by the input inductor $L_{l}$ and the clamping capacitor $C_{2}$, as shown in Fig. $3 c$.

The dc voltage gain $G_{G V D R}$ of the converter in the GVDR mode can be expressed as:

$$
G_{\text {GVDR }}=\frac{V}{V_{I N}}=\frac{n}{1-D},
$$

where $V_{I N}$ and $V_{O U T}$ are the input and the output voltages, correspondingly, $n$ is the turns ratio of the transformer, and $D$ is the duty cycle of the switch $S_{2}$. The voltage stresses of the capacitors in the GVDR mode are presented in Table I.

\section{B. Full-Bridge Rectifier (FBR) Mode}

In this mode, the switch $S_{3}$ is permanently turned OFF and the rectifier is reconfigured to FBR, where the antiparallel diode of the switch $S_{3}$ operates as part of the rectifier bridge (Fig. 4a). The primary part of the converter operates similar 


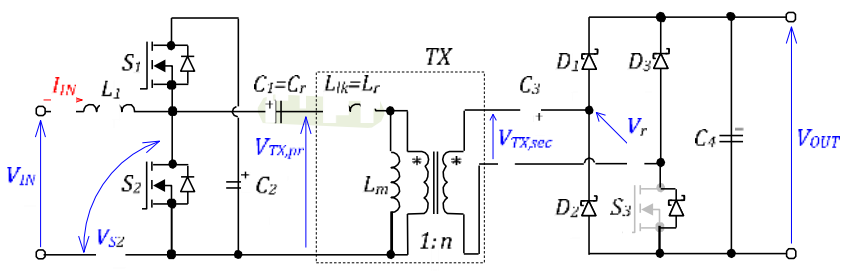

(a)

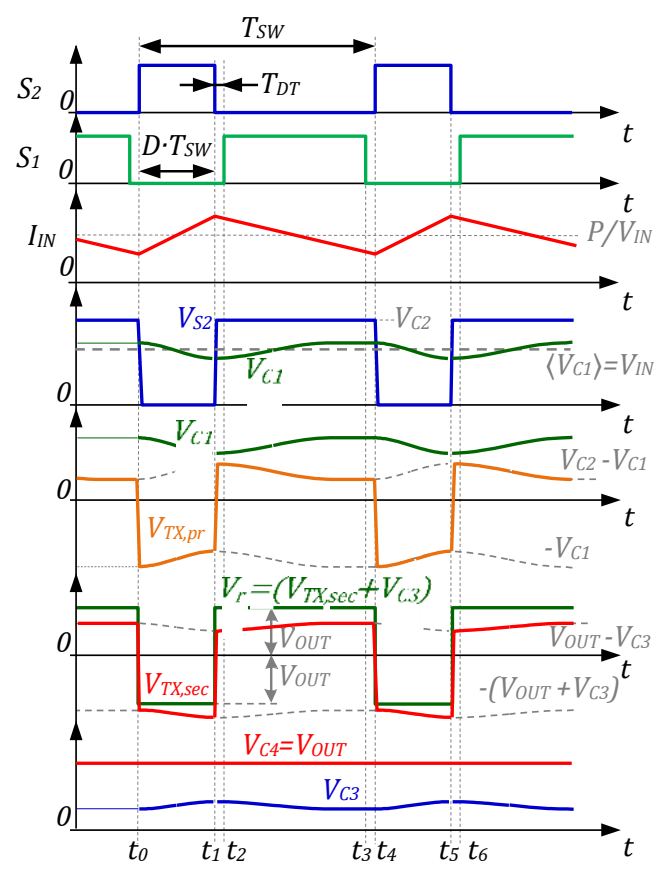

(b)

Fig. 4. Reconfiguration (a) and generalized operating principle $(b)$ of the proposed converter in the FBR mode.

to the GVDR mode; however, due to the properties of the FBR, the converter features twice smaller dc voltage gain:

$$
G_{F B R}=\frac{V}{V_{I N}}=\frac{n}{2 \cdot(1-D)} .
$$

The converter operation in the FBR mode could be described using the equivalent circuits shown in Fig. 5. During the time interval $\left[t_{0} ; t_{1}\right]$, the switch $S_{1}$ forces the input inductor to increase the energy stored inside. Also, the blocking capacitor transfers part of its energy to the output capacitor $C_{4}$ through the isolation transformer, capacitor $C_{3}$, rectifier diodes $D_{2}$ and $D_{3}$, as shown in Fig. $5 a$. During the dead-time intervals $\left[t_{1} ; t_{2}\right]$ and $\left[t_{3} ; t_{4}\right]$, the body diode of the switch $S_{l}$ conducts the current difference between the input current and the transformer current and clamps the voltage of the main power switch $S_{2}$. Polarity of the transformer voltage changes, which results in the conduction of the rectifier diode $D_{l}$ and the body diode of the switch $S_{3}$, as shown in Fig. $5 b$. It could be seen from Fig. $5 c$ that these diodes continue conducting during the time interval $\left[t_{2} ; t_{3}\right]$ after the switch $S_{1}$ is turned ON and charging the capacitor $C_{4}$ from the clamping capacitor $C_{2}$.
The isolation transformer in the BHB converter is supplied with an asymmetric voltage $V_{T X, p r}$ at the following peak values:

$$
\begin{gathered}
=V \quad-V_{C 1} \approx \frac{V_{I N} \cdot D}{1-D} ; \\
\left\{\begin{array}{l}
V_{T X, p r(p o s)} \quad C 2 \\
V_{T X, p r(\text { neg })}=-V_{C 1} \approx-V_{I N} .
\end{array}\right.
\end{gathered}
$$

In the GVDR mode, the rectifier is supplied with asymmetrical bipolar voltage pulses and the voltage stress across the capacitor $C_{3}$ is directly proportional to the input voltage (see Table I). In the FBR mode, the capacitor $C_{3}$ shifts the secondary winding voltage $V_{T X, s e c}$ so the input voltage of the rectifier $\left(V_{r}\right.$ in Fig. $\left.4 a\right)$ has equal absolute values of the positive and negative peak voltages, which are equal to the output voltage $V_{\text {OUT }}$, i.e. the voltage swing of $V_{r}$ equals $2 \cdot V_{O U T}$. Also, the voltage polarity of the capacitor $C_{3}$ depends on the duty cycle value $D$ in the FBR mode (Table I).

The idealized dc voltage regulation characteristics obtained from Eqs. (1) and (2) are shown in Fig. 6. Obviously, at the same duty cycle value, the converter features twice higher dc voltage gain in the GVDR mode compared to the FBR mode. It is shown with the dotted green curve that the transition between the two modes is possible by means of duty cycle step change that results in the same dc voltage gain after switching to the other mode. In practice, a small hysteresis will be required to smoothen the transition process between the two operating modes. This study does not consider a closed loop control system and presents the converter performance in static operation points.

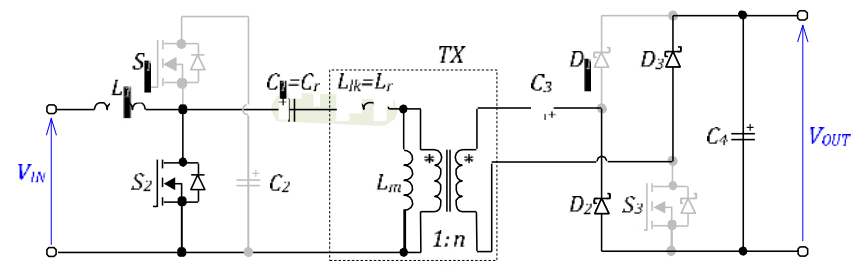

(a)

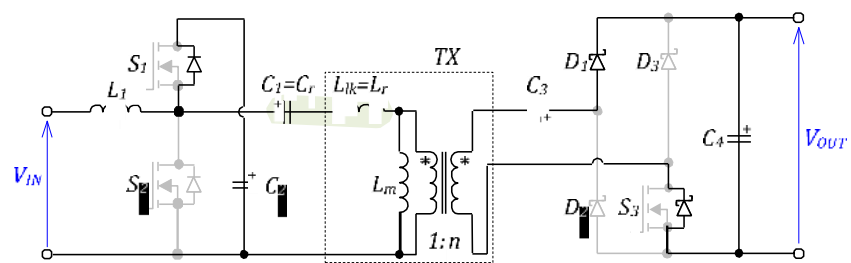

(b)

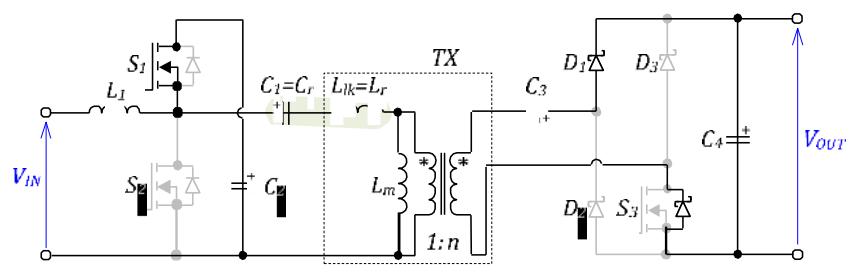

(c)

Fig. 5. Equivalent circuits of the converter operating in the FBR mode for the time intervals $\left[t_{0} ; t_{l}\right](a),\left[t_{1} ; t_{2}\right](b)$ and $\left[t_{2} ; t_{3}\right](c)$ defined in Fig. $4 b$. 


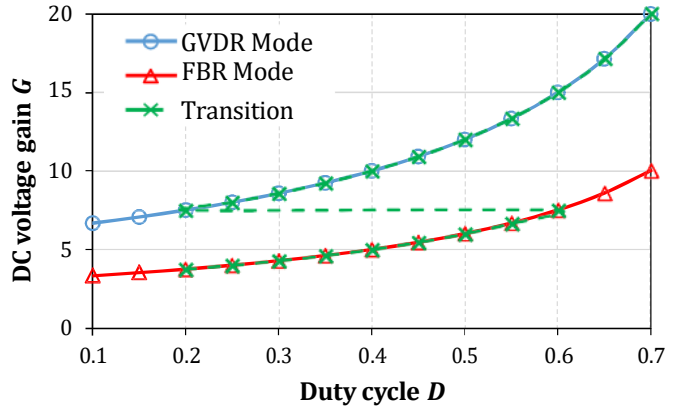

Fig. 6. Idealized voltage regulation characteristics and suggested transition between the GVDR and FBR modes.

\section{EXPERIMENTAL RESULTS}

The experimental prototype of the proposed converter with a rated power of $150 \mathrm{~W}$ was assembled and tested within the input voltage range from $10 \mathrm{~V}$ to $100 \mathrm{~V}$, i.e. 1:10 range, while providing a stabilized voltage of $400 \mathrm{~V}$ at the output. Passive components, semiconductors and control system parameters are described in Table II. It utilizes SiC MOSFET with copacked SiC Schottky barrier diode (SBD) ROHM SCH2080KE, which is the only switch of this type available off-the-shelf. The SBD allows avoiding the operation of the switch body diode with considerably higher forward voltage drop and non-zero reverse recovery losses. Only generic Si switches were used within the BHB switching stage.

Figs. $7 a$ and $7 b$ show the experimental voltage and current waveforms of the proposed converter, which were acquired at $D=0.45$ and input power $P=150 \mathrm{~W}$ for the GVDR and FBR modes, correspondingly. It is seen from Fig. 7 that in both operating modes the converter maintains continuous input current. The voltage swing of $V_{r}$ in the FBR mode is twice wider than in the GVDR mode and equals $2 \cdot V_{\text {OUT }}$, which properly matches the theoretical predictions. The operating currents of the isolation transformer have the sine-like shapes, which confirms the resonant nature of the proposed converter.

The experimental efficiency curves measured at the rated power of $150 \mathrm{~W}$ within the input voltage range from $10 \mathrm{~V}$ to $100 \mathrm{~V}$ are shown in Fig. 8. The transition between the GVDR and FBR modes was realized at $V_{I N}=50 \mathrm{~V}$, which has resulted in a relatively flat efficiency of more than $95 \%$ within a wide input voltage range, i.e. from 20 to $100 \mathrm{~V}$. The peak efficiency of $96.7 \%$ was obtained in the FBR mode at the input voltage

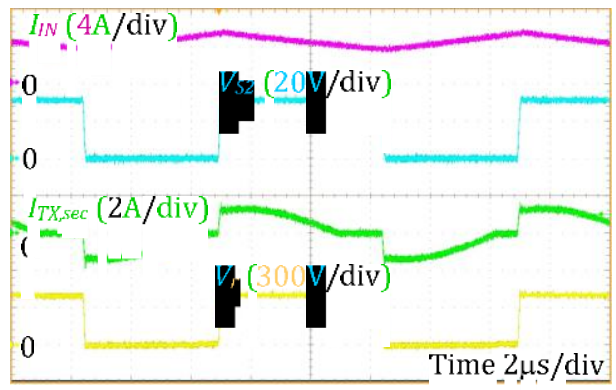

(a)
$V_{I N}=100 \mathrm{~V}$ and the switch duty cycle $D=0.2$. Efficiency drop occurs at $V_{I N}=10 \mathrm{~V}$ due to the high input current of $15 \mathrm{~A}$, resulting in excessive conduction and switching losses that cannot be properly managed by means of the natural cooling of the switch through PCB. Hence, the input current is limited to the value of $15 \mathrm{~A}$.

TABLE I. IDEALIZED VoltAgE StRESSES OF THE CAPACITORS

\begin{tabular}{|c|c|c|c|c|}
\hline \multirow{2}{*}{ Mode } & \multicolumn{4}{|c|}{ Capacitors } \\
\cline { 2 - 5 } GVDR & $\boldsymbol{C}_{\boldsymbol{1}}$ & $\boldsymbol{C}_{\boldsymbol{2}}$ & $\boldsymbol{C}_{3}$ & $\boldsymbol{C}_{\boldsymbol{4}}$ \\
\hline FBR & $V_{I N}$ & $-\frac{V_{I N}}{1-D}$ & $n V_{I N}$ & $-{ }^{\prime \underline{I N}}$ \\
& $V_{I N}$ & $\frac{V_{I N}}{1-D}$ & $\frac{n V_{I N}}{2}\left(\frac{1-2 D}{1-D}\right)$ & $\frac{n V_{I N}}{2(1-D)}$ \\
\hline
\end{tabular}

TABLE II. TYPES AND VALUES OF THE COMPONENTS USED IN A $150 \mathrm{~W}$ EXPERIMENTAL PROTOTYPE

\begin{tabular}{|c|c|}
\hline \multicolumn{2}{|c|}{ Passive components } \\
\hline Input inductor $L_{l}$ & $90 \mu \mathrm{H}$ \\
\hline Resonant capacitor $C_{l}$ & $2 \times 6.8 \mu \mathrm{F}$ \\
\hline Capacitor $C_{2}$ & $47 \mu \mathrm{F}$ \\
\hline VDR capacitor $C_{3}$ & $1 \mu \mathrm{F}$ \\
\hline Output buffering capacitor $C_{4}$ & $3 \mu \mathrm{F}$ \\
\hline Isolation transformer turns ratio $n$ & 6 \\
\hline Leakage inductance $L_{l k}$ & $0.25 \mu \mathrm{H}$ \\
\hline Magnetizing inductance $L_{m}$ & $28 \mu \mathrm{H}$ \\
\hline \multicolumn{2}{|c|}{ Semiconductors } \\
\hline Switches $S_{l}$ and $S_{2}$ & Infineon IPB117N20NFD \\
\hline Driver of switches $S_{l}$ and $S_{2}$ & Analog Devices 2-Channel \\
ADuM3223 $(0 \mathrm{~V} /+9 \mathrm{~V})$
\end{tabular}

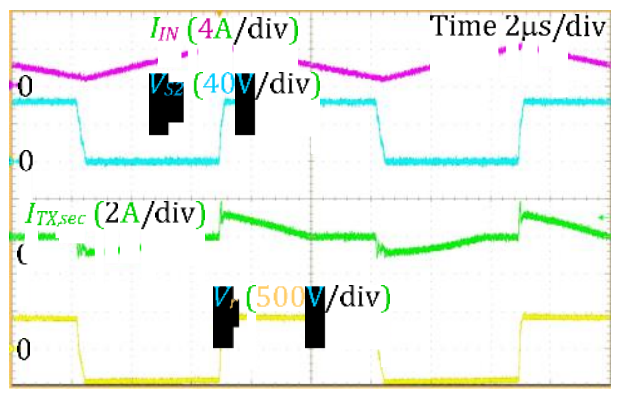

(b)

Fig. 7. Experimental waveforms acquired at $D=0.45$ and $P=150 \mathrm{~W}$ : GVDR mode at $V_{I N}=35 \mathrm{~V}(a)$ and FBR mode at $V_{I N}=70 \mathrm{~V}(b)$. 


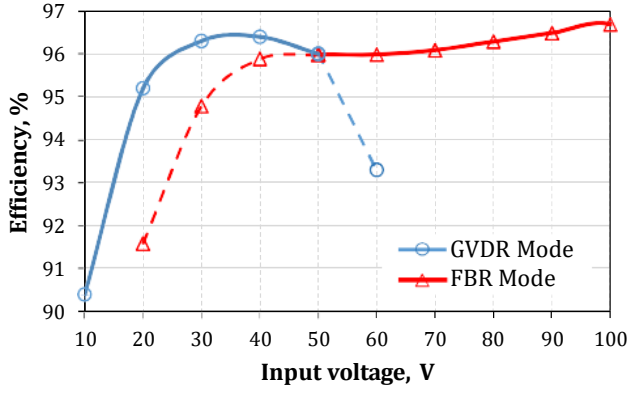

Fig. 8. Measured efficiency of the proposed converter operating at the rated power.

\section{CONCLUSIONS}

A novel high step-up galvanically isolated dc-dc converter was proposed and experimentally validated. Its main operation principle is based on the topology morphing concept, i.e. when the dc gain of the converter could be adjusted by the reconfiguration of the output rectifier. As a result, the proposed converter is capable of regulating a ten-fold variation of the input voltage whilst maintaining the high power conversion efficiency. The continuous input current, low number of components and ultra-wide input voltage regulation range make the converter suitable for the low power renewable energy applications, such as PV microconverters. Theoretical predictions were confirmed by the help of a $150 \mathrm{~W}$ experimental prototype with ten-fold input voltage variation range (i.e. from 10 to $100 \mathrm{~V}$ ) and a peak efficiency close to $97 \%$. Future research will be focused on the optimization of the proposed converter to further enhance its efficiency, especially in the GVDR mode at the lowest values of the input voltage. The resonant properties of the converter need further in-depth study. Detailed design guidelines will be elaborated both for the hardware and control system to ensure the highest possible performance over a wide input voltage and load regulation range.

\section{ACKNOWLEDGMENT}

This research was supported by the Estonian Centre of Excellence in Zero Energy and Resource Efficient Smart Buildings and Districts, ZEBE, grant 2014-2020.4.01.15-0016 funded by the European Regional Development Fund.

\section{REFERENCES}

[1] M. Malinowski, A. Milczarek, D. Vinnikov, A. Chub, "Wind energy systems," Chap. 12 in Power Electronic Converters and Systems: Frontiers and Applications, Ed. A. M. Trzynadlowski, London, UK: IET, 2015, pp. 351-394, DOI: 10.1049/PBPO074E_ch12.

[2] A. Chub, T. Jalakas, A. Milczarek, A. Kallaste and M. Malinowski, "Grid integration issues of PMSG-based residential wind turbines," Proc. of 2014 Electric Power Quality and Supply Reliability Conference (PQ), Rakvere, 2014, pp. 147-154.

[3] A. Chub, O. Husev, A. Blinov and D. Vinnikov, "Novel Isolated Power Conditioning Unit for Micro Wind Turbine Applications," in IEEE Transactions on Industrial Electronics, vol. 64, no. 7, pp. 5984-5993, July 2017.
[4] D. Vinnikov, A. Chub, E. Liivik and I. Roasto, "High-Performance QuasiZ-Source Series Resonant DC-DC Converter for Photovoltaic ModuleLevel Power Electronics Applications," in IEEE Transactions on Power Electronics, vol. 32, no. 5, pp. 3634-3650, May 2017.

[5] D. Vinnikov, R. Kosenko, A. Chub and E. Liivik, "Shade-Tolerant Photovoltaic Microinverter with Time Adaptive Seamless P-V Curve Sweep MPPT," in Proc. of 2017 19th European Conference on Power Electronics and Applications (EPE'17 ECCE-Europe), Warsaw, 2017.

[6] D. Vinnikov, A. Chub, E. Liivik and F. Blaabjerg, "Magnetically Integrated High Step-Up Resonant DC-DC Converter for Distributed Photovoltaic Systems," in Proc. of 43nd Annual Conference of the IEEE Industrial Electronics Society (IECON'2017), Beijing, 2017.

[7] Y. Lu, H. Wu, K. Sun and Y. Xing, "A Family of Isolated Buck-Boost Converters Based on Semiactive Rectifiers for High-Output Voltage Applications," in IEEE Transactions on Power Electronics, vol. 31, no. 9, pp. 6327-6340, Sept. 2016.

[8] T. LaBella, W. Yu, J. S. Lai, M. Senesky and D. Anderson, "A Bidirectional-Switch-Based Wide-Input Range High-Efficiency Isolated Resonant Converter for Photovoltaic Applications," in IEEE Transactions on Power Electronics, vol. 29, no. 7, pp. 3473-3484, July 2014.

[9] T. LaBella and J. S. Lai, "A Hybrid Resonant Converter Utilizing a Bidirectional GaN AC Switch for High-Efficiency PV Applications," in IEEE Transactions on Industry Applications, vol. 50, no. 5, pp. 34683475, Sept.-Oct. 2014.

[10] D. Vinnikov, A. Chub, E. Liivik and I. Roasto, "High-Performance QuasiZ-Source Series Resonant DC-DC Converter for Photovoltaic ModuleLevel Power Electronics Applications," in IEEE Transactions on Power Electronics, vol. 32, no. 5, pp. 3634-3650, May 2017.

[11] D. Vinnikov, A. Chub, R. Kosenko, J. Zakis and E. Liivik, "Comparison of Performance of Phase-Shift and Asymmetrical Pulse Width Modulation Techniques for the Novel Galvanically Isolated Buck-Boost DC-DC Converter for Photovoltaic Applications," in IEEE Journal of Emerging and Selected Topics in Power Electronics, vol. 5, no. 2, pp. 624-637, June 2017.

[12] A. Chub, D. Vinnikov, R. Kosenko and E. Liivik, "Wide Input Voltage Range Photovoltaic Microconverter With Reconfigurable Buck-Boost Switching Stage," in IEEE Transactions on Industrial Electronics, vol. 64, no. 7, pp. 5974-5983, July 2017.

[13] S. Jiang, D. Cao, Y. Li and F. Z. Peng, "Grid-Connected Boost-HalfBridge Photovoltaic Microinverter System Using Repetitive Current Control and Maximum Power Point Tracking," in IEEE Transactions on Power Electronics, vol. 27, no. 11, pp. 4711-4722, Nov. 2012.

[14] E. Liivik, A. Chub, R. Kosenko and D. Vinnikov, "Low-cost photovoltaic microinverter with ultra-wide MPPT voltage range," in Proc. 2017 6th International Conference on Clean Electrical Power (ICCEP), Santa Margherita Ligure, 2017, pp. 46-52.

[15] K. Fathy, H. W. Lee, T. Mishima and M. Nakaoka, "Boost-Half Bridge Single Power Stage PWM DC-DC Converter for Small Scale Fuel Cell Stack," in Proc. of 2006 IEEE International Power and Energy Conference, Putra Jaya, 2006, pp. 426-431.

[16] C. Park and S. Choi, "Quasi-Resonant Boost-Half-Bridge Converter With Reduced Turn-Off Switching Losses for $16 \mathrm{~V}$ Fuel Cell Application," in IEEE Transactions on Power Electronics, vol. 28, no. 11, pp. 4892-4896, Nov. 2013.

[17] Jianhong Zeng, Jianping Ying and Qingyou Zhang, "A novel DC/DC ZVS converter for battery input application," in Proc. of 2002 IEEE Applied Power Electronics Conference and Exposition (APEC), Dallas, TX, 2002, vol. 2, pp. 892-896.

[18] B. York, W. Yu and J. S. Lai, "An Integrated Boost Resonant Converter for Photovoltaic Applications," in IEEE Transactions on Power Electronics, vol. 28, no. 3, pp. 1199-1207, March 2013.

[19] Y. Shen, H. Wang, Z. Qin, F. Blaabjerg and A. A. Durra, "A reconfigurable series resonant DC-DC converter for wide-input and wide-output voltages," Proc. of 2017 IEEE Applied Power Electronics Conference and Exposition (APEC), Tampa, FL, 2017, pp. 343-349. 